\title{
Validation and description of two new north-western Australian Rainbow skinks with multispecies coalescent methods and morphology
}

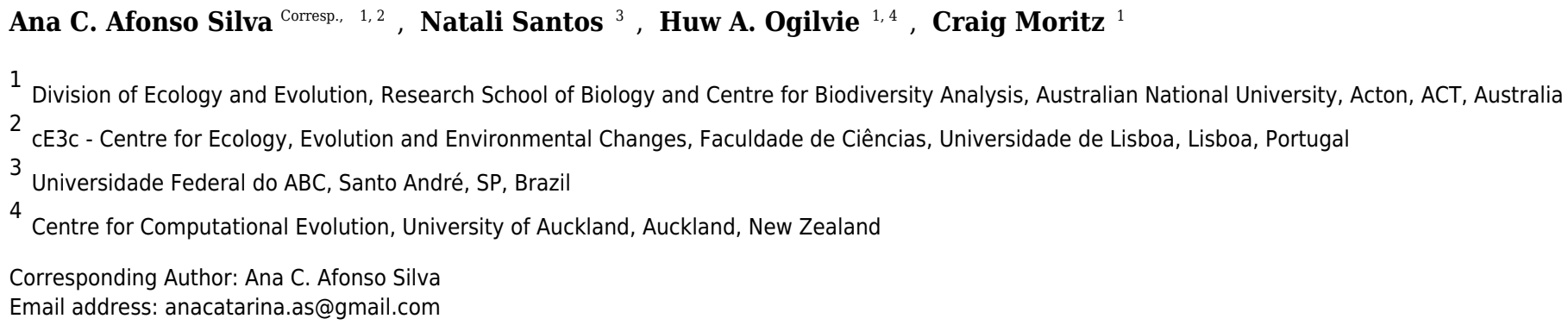

While methods for genetic species delimitation have noticeably improved in the last decade, this remains a work in progress. Ideally, model based approaches should be applied and considered jointly with other lines of evidence, primarily morphology and geography, in an integrative taxonomy framework. Deep phylogeographic divergences have been reported for several species of Carlia skinks, but only for some eastern taxa have species boundaries been formally tested. The present study does this and revises the taxonomy for two species from northern Australia, Carlia johnstonei and C. triacantha. We introduce an approach that is based on the recently published method StarBEAST2, which uses multilocus data to explore the support for alternative species delimitation hypotheses using Bayes Factors (BFD). We apply this method, jointly with two other multispecies coalescent methods, using an extensive (from 2163 exons) data set along with measures of 11 morphological characters. We use this integrated approach to evaluate two new candidate species previously revealed in phylogeographic analyses of rainbow skinks (genus Carlia) in Western Australia. The results based on BFD StarBEAST2, BFD* SNAPP and BPP genetic delimitation, together with morphology, support each of the four recently identified Carlia lineages as separate species. The BFD StarBEAST2 approach yielded results highly congruent with those from BFD* SNAPP and BPP. This supports use of the robust multilocus multispecies coalescent StarBEAST2 method for species delimitation, which does not require a priori resolved species or gene trees. Compared to the situation in C. triacantha, morphological divergence was greater between the two lineages within Kimberley endemic $C$. johnstonei, which also had deeper divergent histories. This congruence supports recognition of two species within $C$. johnstonei. Nevertheless, the combined evidence also supports recognition of two taxa within the more widespread $C$. triacantha. With this work, we describe two new species, Carlia insularis sp. nov and Carlia 
isostriacantha sp. nov. in the northwest of Australia. This contributes to increasing recognition that this region of tropical Australia has a rich and unique fauna. 
1 Title

2 Validation and description of two new north-western Australian Rainbow skinks with

3 multispecies coalescent methods and morphology

4

5 Authors: Ana C. Afonso Silva ${ }^{1,2}$, Natali Santos ${ }^{3}$, Huw A. Ogilvie ${ }^{1,4}$ and Craig Moritz ${ }^{1}$

7 Affiliations

$8{ }^{1}$ Division of Ecology and Evolution, Research School of Biology and Centre for Biodiversity

9 Analysis, Australian National University, Acton, ACT, Australia.

$10{ }^{2} \mathrm{cE} 3 \mathrm{c}-$ Centre for Ecology, Evolution and Environmental Changes, Faculdade de Ciências,

11 Universidade de Lisboa, Lisboa, Portugal.

12 Universidade Federal do ABC, Santo André, SP, Brazil.

$13{ }^{4}$ Centre for Computational Evolution, University of Auckland, Auckland, New Zealand.

14

15 Corresponding author: Ana C. Afonso Silva

16 e-mail: anacatarina.as@gmail.com

17

18

19

20

21

22

23 


\section{Abstract}

While methods for genetic species delimitation have noticeably improved in the last

decade, this remains a work in progress. Ideally, model based approaches should be applied and considered jointly with other lines of evidence, primarily morphology and geography, in an integrative taxonomy framework. Deep phylogeographic divergences have been reported for several species of Carlia skinks, but only for some eastern taxa have species boundaries been formally tested. The present study does this and revises the taxonomy for two species from northern Australia, Carlia johnstonei and C. triacantha.

We introduce an approach that is based on the recently published method StarBEAST2, which uses multilocus data to explore the support for alternative species delimitation hypotheses using Bayes Factors (BFD). We apply this method, jointly with two other multispecies coalescent

37 methods, using an extensive (from 2163 exons) data set along with measures of 11 morphological characters. We use this integrated approach to evaluate two new candidate species previously revealed in phylogeographic analyses of rainbow skinks (genus Carlia) in Western Australia.

The results based on BFD StarBEAST2, BFD* SNAPP and BPP genetic delimitation, together with morphology, support each of the four recently identified Carlia lineages as separate species. The BFD StarBEAST2 approach yielded results highly congruent with those

44 from BFD* SNAPP and BPP. This supports use of the robust multilocus multispecies coalescent

45 StarBEAST2 method for species delimitation, which does not require a priori resolved species or 46 gene trees. 
47 Compared to the situation in C. triacantha, morphological divergence was greater between

48 the two lineages within Kimberley endemic C. johnstonei, which also had deeper divergent

49 histories. This congruence supports recognition of two species within C. johnstonei.

50 Nevertheless, the combined evidence also supports recognition of two taxa within the more

51 widespread C. triacantha.

52 With this work, we describe two new species, Carlia insularis sp. nov and Carlia

53 isostriacantha sp. nov. in the northwest of Australia. This contributes to increasing recognition

54 that this region of tropical Australia has a rich and unique fauna.

55

56

57

58

59

60

61

62

63

64

65

66

67

68

69 70

\section{Introduction}

Cryptic species - when two or more distinct species are inaccurately classified under one species name (Bickford et al., 2007) - present great challenges for taxonomy and species delimitation due to the desirability of validating candidate species using multiple lines of evidence (Fujita et al., 2012). But for biodiversity assessment and conservation reasons the need to properly describe species diversity is greater than ever (Bickford et al., 2007). In the same way, there is a concern that molecular data may promote taxonomic inflation by 'over splitting' divergent populations into candidate species (Isaac, Mallet \& Mace, 2004; Hedin, Carlson \& Coyle, 2015). The creation of more reliable and robust species delimitation approaches in the last decade has attempted to address this concern (Rannala, 2015).

To more robustly infer species boundaries, the use of integrative taxonomy is increasingly common (Bickford et al., 2007; Padial et al., 2010). The objective of this approach is to corroborate taxonomic validity with independent, distinct types of evidence. Given deep genetic divergence, fixed morphological differences are not necessary to diagnose species boundaries since speciation itself does not require phenotypic characters to evolve at the same rate as the 
71 genome (Leaché \& Fujita, 2010). Therefore, in taxa with inherently conservative morphology, it

72 may be that the primary evidence for distinct species will come from genetic data.

73 Species delimitation consists of two potentially complementary approaches: discovery

74 methods that do not require a priori assignment of samples before analysis, and validation

75 methods that test hypotheses based on samples already assigned to candidate species (Ence \&

76 Carstens, 2011). When candidate lineages are already identified, validation approaches are more

77 robust because they explicitly model the process of lineage diversification (Carstens et al., 2013).

78 This is especially so when there is a substantial number of informative genes, independent of

79 those used to suggest candidate taxa. Model-based multilocus approaches that use the

80 multispecies coalescent (MSC) are advantageous because they account for coalescent processes

81 when estimating phylogenetic relationships (Edwards et al., 2016). And for species delimitation,

82 objective and transparent model-based approaches are relevant, because they have the potential

83 to reduce investigator-driven biases (Fujita et al., 2012). These methods can consider gene tree

84 incongruence due to incomplete lineage sorting, variation in molecular sequences and variation

85 in demographic parameters (Leaché \& Fujita, 2010). With this in mind, Carstens et al. (2013)

86 recommend the best approach for species delimitation is to use multiple methods. Further,

87 Rannala (2015) suggests that this should only be done when methods have algorithmically

88 similar assumptions. However, we also note that MSC methods can over split - revealing high

89 structured populations (or ephemeral species; Rosenblum et al., 2012) - rather than long isolated

90 species, depending on the nature of the speciation process (Sukumaran \& Knowles, 2017).

91 Hence, species delimitation will always be more secure when taxa delimited using genetic

92 methods are somehow corroborated by alternative sources of data (Oliver, Keogh \& Moritz, 93 2014). 

phylogeographic structure and history differs between a climatic generalist and specialist, found two deeply divergent lineages within each of Carlia johnstonei Storr, 1974 and C. triacantha Mitchell, 1953 (Fig. 1). These sister taxa (Dolman \& Hugall, 2008) have contrasting distributions, with the former being endemic to the Kimberley and the latter being widespread across northern Australia. The lineages within C. johnstonei are likely allopatric, with the nominal lineage (Johnstonei A) being found across the north and western Kimberley and the newly identified lineage (Johnstonei B) being endemic to islands off the coast of the northwest Kimberley (Fig. 1). Conversely, the two lineages of C. triacantha likely overlap geographically, with the nominal lineage being widespread across north and central Australia (Triacantha A) and the newly identified lineage (Triacantha B) found within the Kimberley and scattered locations in the central Northern Territory (Fig. 1). structure for both mtDNA and large numbers of exons (e.g. Potter et al., 2016), and, where contact zones have been examined in detail, there is evidence of strong reproductive isolation between the more deeply divergent (but phenotypically cryptic) lineages (Phillips, Baird \& Moritz, 2004; Singhal \& Moritz, 2013). However, recent species delimitation and taxonomic revisions have focussed more on Carlia from the eastern woodlands and placed a greater emphasis on morphology (e.g. Hoskin \& Couper, 2012; Hoskin, 2014). There is a need to reexamine the systematics of northern Australian Carlia, and here we have the opportunity to exploit large multilocus datasets (Bragg et al., 2015) to do that integrated with morphology. This

115 is particularly relevant for Kimberley biodiversity, since there have been recent efforts to 116 discover and describe new species (Köhler, 2011; Oliver et al., 2014, 2016; Andersen et al., 
117 2014; Ellis, 2016) in this still relatively unknown and remote region in the northwestern of 118 Australia.

119 We reanalyse the extensive multilocus data used in Afonso Silva et al. (2017) using 120 robust species delimitation methods, together with morphological analysis to validate species

121 hypotheses. Following Rannala (2015), we use three algorithmically similar methods to validate

122 potential new species. We apply BPP (Yang \& Rannala, 2014) and two approaches using Bayes

123 Factors to test species hypotheses: a SNP based approach, BFD* (Leaché et al., 2014) using

124 SNAPP (Bryant et al., 2012) and a sequence-based approach, BFD with the recently developed

125 StarBEAST2 method (Ogilvie, Bouckaert \& Drummond, 2017). We consider three potential

126 species hypotheses: (i) only the two currently defined species are separated; (ii) a three-species

127 hypothesis - two species corresponding to the two more deeply divergent lineages of $C$.

128 johnstonei, but collapsing the less divergent lineages within C. triacantha; and (iii) a four-

129 species hypothesis - all four lineages correspond to different species. Using an integrative

130 taxonomic approach, we present and analyse morphological data to test for congruent differences

131 between all identified genetic lineages. Considering all lines of evidence, we then formally

132 describe the new species and identify diagnostic traits, for both morphology and gene sequences.

133 Genetic diagnostic traits include SNPs from available mtDNA ND4 gene sequences (Afonso

134 Silva et al. 2017), following Renner's (2016) suggestion to provide simple genetic diagnostics, 135 particularly for morphologically similar species groups.

137 Materials \& Methods

138 We used exon capture data to perform validation analyses and sequences of the mtDNA

139 ND4 gene to identify diagnostic SNPs, and, also measured, analysed and identified diagnostic 
140 morphological traits. We obtained sequences for the genetic data from Afonso Silva et al. (2017)

141 (Dryad Digital Repository http://dx.doi.org/10.5061/dryad.jj1t). These included mtDNA

142 sequence data of 101 C. johnstonei and 99 C. triacantha throughout both species' distribution,

143 for which we had specimens to do morphological analysis (Table S1, Fig. S1).

144 See Afonso Silva et al. (2017) for more detail about how the exon capture data was

145 obtained. In summary, the data was retrieved from a custom set of loci designed from

146 transcriptomes of Carlia and a couple of related genera (Bragg et al., 2015). After similar

147 processing to Bragg et al. (2015), the final dataset contained a total of 51 samples with average

148 of 40x coverage and approximately 2800 loci per sample. For the validation analyses, we

149 retrieved data from the 20 geographically dispersed samples as used for species tree estimation in

150 Afonso Silva et al. (2017) (Fig. 1, Table S1). These correspond to five individuals for each of the

151 four lineages previously identified in Afonso Silva et al. (2017) (Fig. 1, Table 1), using the same

152 C. amax samples as an outgroup (from Potter et al., 2016) that were used in that study. For these

153 analyses, we required aligned haplotype sequences, for which we employed GATK (v3.3,

154 McKenna et al., 2010) which was also used to identify heterozygous sites and mask sites with a

155 low-quality genotype call $(\mathrm{GQ}<20)$. Here, we generated phased haplotypes using the individual

156 overlapping sequencing reads to phase heterozygous sites within target loci and then used one

157 haplotype per sample in later analyses.

158 We then used the EAPhy pipeline (Blom 2015 v.1.2;

$159 \mathrm{https}: / /$ github.com/MozesBlom/EAPhy) to realign, filter and export alignments with complete

160 data into NEXUS and PHYLIP format, as well as two sets of SNPs in FASTA format (using 0.2

161 as maximum proportion of Ns for each site, one SNP chosen randomly per gene and excluding

162 singletons). 


\section{Genetic species validation}

We applied three multispecies coalescent validation approaches to investigate species

166

167 168 169

170

171

172

173

174 175

176

177

178

179

180

181

182

183

184

185

boundaries: Bayesian Phylogenetics and Phylogeography (BPP v3.3; Yang \& Rannala, 2014),

BFD (Bayes factor delimitation; Grummer et al. 2014) StarBEAST2 using multilocus data (Ogilvie, Bouckaert \& Drummond, 2017), and BFD* SNAPP using SNP data (Leaché et al., 2014).

For the BPP analysis, we randomly selected two exon sets (to avoid unforeseen biases), each with 100 loci of between $250 \mathrm{bp}$ and $1000 \mathrm{bp}$, to check for consistent results. The MSC assumes no recombination within loci, and free recombination among loci (Degnan et al., 2009). We are confident of satisfying the latter condition, as our exons are all derived from different genes (Bragg et al., 2015). Lanier \& Knowles (2012) showed that intra-locus recombination had little effect in species-tree estimates under the MSC; however Potter et al. (2016) found that it can affect species delimitation. Hence, to further evaluate this effect, we used the program $I M g c$ (Woerner, Cox \& Hammer, 2007) to extract optimal recombination-filtered blocks (no fourgamete violations) and repeated BPP analysis for comparison. We performed joint Bayesian species delimitation and species tree estimation (method A11, Yang, 2015). This method uses the multispecies coalescent model to compare different models of species delimitation and species phylogeny in a Bayesian framework, accounting for incomplete lineage sorting due to ancestral polymorphism and gene tree species tree conflicts (Yang \& Rannala, 2010, 2014; Rannala \& Yang, 2013). Ancestral population size parameters (theta) were set to gamma prior $\mathrm{G}(2,1000)$, with mean $2 / 1000=0.002$ and the divergence time at the root of the species tree (tau) was assigned to $G(2,2000)$, while the other divergence time parameters were assigned to the 
186 Dirichlet prior (Yang \& Rannala, 2010: equation 2). Preliminary analyses run using different 187 combination of gamma priors, as suggested in Yang (2015), produced similar results, suggesting 188 that our results are robust to the priors used. The phylogeny obtained in Afonso Silva et al. 189 (2017) was used as a starting tree and all columns in the alignment were used in the likelihood 190 calculation. Each exon set analysis was independently run twice to confirm consistency between 191 runs, with a burn-in of 50,000 and a sampling frequency of five iterations for a total of 500,000 192 generations.

193 Bayes factor delimitation (BFD; Grummer, Bryson \& Reeder, 2014) is an approach that 194 compares the marginal likelihoods of competing species delimitation hypotheses using Bayes 195 factors. To apply this approach, we ran two MSC methods to test our three potential hypotheses 196 using C. amax as an outgroup: (i) a scenario with two species (C. johnstonei and C. triacantha), 197 (ii) a scenario with three species (lineages Johnstonei A, Johnstonei B and C. triacantha) and 198 (iii) a scenario with four species (with both lineages from C. triacantha and C. johnstonei as 199 separate species).

StarBEAST2 v0.13.5 is a recently released sequence-based approach that reconstructs 201 species trees with more flexibility than BPP (Ogilvie, Bouckaert \& Drummond, 2017), and so 202 provides an alternative MSC method to investigate species delimitation with Bayes factors 203 (BFD). To verify consistency, we randomly selected another two sets of exons, each with 20 loci 204 between 250 and 1000 bp. We then used jModelTest v2.1.10 (Guindon, Gascuel \& Rannala, 205 2003; Darriba et al., 2012) to calculate nucleotide substitution model likelihood scores for each 206 locus and to estimate optimal model using BIC (Supplemental Table S2). All BFD StarBEAST2 207 analyses were performed using a strict clock model, for 100,000,000 generations, with data 208 sampled every 10,000 generations, the first $10 \%$ of each run was discarded as burn-in and priors 
209 as in Table S3. For each analysis, two BFD StarBEAST2 replicates were conducted to ensure 210 convergence and assessed using ESS values with Tracer v1.6 (Rambaut et al., 2015). We used

211 stepping-stone sampling (Leaché et al., 2014) to determine the marginal likelihoods of four, three

212 and two species (plus outgroup). All stepping-stone analyses used 16 steps with a beta

213 distribution $\alpha$ parameter of 0.1 to optimise the power posterior discretization (Xie et al., 2010).

214 The resulting marginal likelihoods were then used to compute Bayes factors (Kass \& Raftery, 215 1995), quantifying the support for each species delimitation hypothesis against all others under 216 consideration. The final tree was obtained by combining posterior replicates with LogCombiner 217 (Drummond \& Rambaut, 2007) and summarised using maximum clade credibility trees, after 218 exclusion of 10\% burn-in, with TreeAnnotator v1.7.2 (Drummond \& Rambaut, 2007).

219 To use an approach that considers evidence from all available loci, we selected two 220 independent SNP sets by sampling one SNP at random from each locus out of 2,163 total 221 available loci and estimated species trees for each scenario using SNAPP (Bryant et al., 2012).

222 We ran all analysis for 500,000 generations sampling every 500, with two replicates to ensure 223 convergence and priors as in Table S3. After assessing convergence between runs and exon sets

224 we proceeded to Bayes factor delimitation as described previously.

225

226 Morphological data collection

227 We analysed 200 specimens from the Museum and Art Gallery of the Northern Territory

228 (MAGNT), Museum Victoria (MV), South Australian Museum (SAM), Western Australian

229 Museum (WAM) and recently-collected specimens held at the Australian National University

230 (with ANU ethical approval number A2012/14) (Fig. 1, Table S1). All analysed specimens were 231 also sequenced for the mtDNA ND4 gene in Afonso Silva et al. (2017) (Fig. S1), with a total of 
23266 examined specimens for Johnstonei A, 35 for Johnstonei B, 31 for Triacantha A and 68 for 233 Triacantha B.

234 We examined five morphometric characters taken to the nearest $0.1 \mathrm{~mm}$ with Mitutoyo 235 electronic callipers: snout-vent length (SVL), axilla-groin length (AGL), head length (HL)

236 measured from anterior edge of tympanum to snout, head width (HW) measured at widest point

237 of the head, and head depth (HD) measured at parietal scales. In order to minimize error, we used 238 a dissecting microscope Leica MZ8 (equipped with camera Leica MC120 HD) for which 239 forelimb (FLL) and hindlimb length (HLL) were measured through photographs using ImageJ 240 (Abràmoff, Magalhães \& Ram, 2004) (as in Fig. S3); as well as four additional smaller features: 241 nasals separation (NS), ear aperture length (EAL), palpebral disc length (PDL) and eye to ear 242 distance (EED) (as explained in Fig. S3).

243 We also assessed seven meristic characters using photographs: supralabials, infralabials, 244 supraciliaries, lamellae under the 4th toe (from claw sheath to junction of 3rd and 4th toes), 245 lamellae under the 3rd finger (from claw sheath to the junction of the 2nd and 3rd fingers), the 246 mode of number of keels across the mid-dorsal line scales and the ear lobule numbers. These 247 traits were counted as suggested by Cogger (2014) and similarly to Hoskin \& Couper (2012).

248 Measurements and scales were generally analysed from the left side of the specimen, unless 249 prevented by damage or poor preservation. All described measurements were collected in 250 millimetres (mm).

251 For the ensuing species descriptions, we also measured the tail length and the distance 252 between prefrontals if not in contact, but these traits were not used in the morphological analysis 253 due to high level of missing data. For the designated holotypes, we additionally counted the 254 number of midbody scale rows, vertebral (from the occiput to the edge of the hind limb along the 
255 mid dorsal line) and ventral scales (from mental scale to the edge of cloaca).

256

257 Morphological analyses

258 We investigated the relationship of each linear measurement with size (per mtDNA

259 lineage), by plotting each variable against SVL and by comparing box plots of raw and size

260 corrected measurements. After removing samples with missing data, all measurements were log-

261 transformed to reduce their variance allowing a more conservative assessment of differences

262 between mtDNA lineages. We then extracted size-corrected residuals from regressions between

263 SVL and each measurement as a size-corrected log-transformed dataset. We investigated

264 normality and heteroscedasticity after variable correction using density plots, Shapiro-Wilk test

265 and Levene's test. Multivariate normality was assessed with the Henze-Zirkler's Multivariate

266 Normality Test in the MVN package (Korkmaz, Goksuluk \& Zararsiz, 2014).

267 In order to assess the morphometric distinctiveness of these lineages, we conducted

268 Principal Component analyses on the log-transformed and on the size-corrected log-transformed

269 (excluding SVL) datasets for each species. We used the prcomp function (stats package) with all

270 measurement variables centred and plotted principal component 1 (PC1) against PC2, with a

$27175 \%$ confidence ellipse probability threshold (ggplot2 package, Wickham 2016).

272 To statistically evaluate whether the lineages are significantly different and which variables

273 are contributing to this, we analysed log-transformed and size-corrected log-transformed

274 measurements with a MANOVA, and confirmed the significance of non-normal variables with

275 the non-parametric Wilcoxon test (stats package). Relevant meristic data was analysed

276 independently with a generalized linear modelling with a Poisson distribution (stats package)

277 since these are count data and not continuous variables. 
279 the accuracy in predicting assignment of lineage by applying a linear discriminant analysis

280 (LDA) with jackknife cross-validation implemented in the package MASS (Ripley et al., 2013).

281 Due to the presence of non-normal variables, we also applied a Random Forest (RF) analysis

282 using the package randomForest (Liaw \& Wiener, 2002).

283 We investigated the effect of possible outliers in the data by calculating, for each of the

284 variables, interquartile range scores (function scores in outliers package, Komsta, 2011) to

285 identify samples with outliers and then perform a MANOVA with this dataset. Removing

286 outliers decreases $14 \%$ and $6 \%$ of analysed specimens for C. johnstonei and C. triacantha,

287 respectively. Since some of these outliers could represent expected phenotypic variation across

288 these species distribution and the overall results were similar, we present the analyses with all 289 individuals.

290 To account for the insufficient information on sex, we performed a linear model containing 291 sex and mtDNA lineage, using the available sexed individuals, which showed no difference in 292 SVL between males and females in either $C$. johnstonei or C. triacantha. This suggests sex 293 differences cannot explain our observed results, so we also present the analyses with all 294 individuals.

295 We performed all analyses in R v.3.3.1 (R Core Team, 2016) and all the data, input files, 296 code and morphological results are available at https://dx.doi.org/10.6084/m9.Figshare.4621963.

298 Molecular diagnostics

299 Following the recommendation of Renner (2016), we visually identified diagnostic SNPs 300 within the ND4 mtDNA gene using all Afonso Silva et al. (2017) sequences with Genbank 
301 accessions codes MF083173-MF083508 in Geneious v.7.1.9 (http:/www.geneious.com, Kearse

302 et al., 2012). Using as a reference an available skink mitogenome from Scincella vandenburghi

303 (Park et al., 2016), we selected the available diagnostic SNPs per lineage within each species,

304 where the nucleotide difference would correspond to an amino acid substitution.

305

306 The electronic version of this article in Portable Document Format (PDF) will represent a 307 published work according to the International Commission on Zoological Nomenclature (ICZN),

308 and hence the new names contained in the electronic version are effectively published under that

309 Code from the electronic edition alone. This published work and the nomenclatural acts it

310 contains have been registered in ZooBank, the online registration system for the ICZN. The

311 ZooBank LSIDs (Life Science Identifiers) can be resolved and the associated information viewed

312 through any standard web browser by appending the LSID to the prefix http://zoobank.org/. The

313 LSID for this publication is: urn:lsid:zoobank.org:pub:A7B29F16-079F-48BA-B4BE-

314 3EC9A3D80D34. The online version of this work is archived and available from the following

315 digital repositories: PeerJ, PubMed Central and CLOCKSS.

\section{Results}

MSC Species delimitation

319 All three MSC approaches assigned more support to the four-species hypothesis than either 320 the two- or three-species hypotheses (Table 1).

321 Both BPP analyses, each with independent drawn sets of genes, yielded the same species tree

322 (Fig. 2) and a posterior probability (PP) equal to 1 for five delimited species (all four lineages 
323 plus the outgroup). The analyses processed with IMgc to exclude blocks with no four-gamete

324 violations from within alignments, returned similar results with $\mathrm{PP}=1$ for four lineages plus

325 outgroup. However, while topology for the original datasets was as expected by $99 \%$ of the

326 models (Fig. 2), for each gene set without recombining blocks only $64 \%$ and $85 \%$ of the models

327 supported the same topology.

328 For both BFD StarBEAST2 and BFD* SNAPP, Bayes Factors (BF) were obtained by 329 subtracting the two-species hypothesis from both the three-species hypothesis as well the four330 species hypothesis, and multiplying the difference of marginal likelihoods by a factor of two.

331 The BFs for both the BFD StarBEAST2 and BFD* SNAPP analyses were $>10$ for the four-

332 species hypothesis relative to the two- or three-species hypotheses (Table 1), which corresponds

333 to decisive evidence for this model (Kass \& Raftery, 1995). The marginal likelihood results

334 were of similar magnitude across the two gene datasets for BFD StarBeast2 and across the two

335 SNP datasets for BFD* SNAPP (Table 1, Fig. S2), although BFs were much higher for the latter.

336 The species tree topology with the main lineages was assessed in Afonso Silva et al. (2017)

337 using the ASTRAL summary species tree method (Fig. 1), but here species trees were also

338 estimated by BPP, StarBEAST2 and SNAPP. StarBEAST2 and SNAPP all returned majority

339 support for the ASTRAL topology. For gene sets 1 and 2, StarBEAST2 support for the ASTRAL

340 topology was $97 \%$ and $63 \%$, respectively. Support was higher using SNAPP at $95 \%$ and $>99 \%$

341 for SNP set 1 and 2, respectively.

342

343 Morphological analysis

344 The morphological measurements suggest that snout-vent length (SVL) is an important

345 differentiating trait between candidate species within each of C. johnstonei and C. triacantha 
346 (Fig. 3, S4). Thus, further analyses were conducted also using size-corrected log-transformed 347 variables (Fig. S5), so we could assess if the lineages were statistically different after accounting 348 for SVL differences. For multivariate analyses, individuals with missing data were removed and 349 after size correction some variables were still not normal (Table S4,5), but were multivariate 350 normal for both $C$. johnstonei $(\log$-transformed $H Z$ p-value $=0.056$, size corrected $H Z$ p-value $=$ $3520.272)$.

In the PCA results for $C$. johnstonei with only log-tranformed data (including SVL), the first 354 axis (PC1) explained $74.4 \%$ of the total variation with all variables loading uniformly (and hence 355 size-related) and the second axis (PC2) only explained $7.2 \%$ of variation (Fig. 3A, S6A). By contrast, in the PCA with the size corrected dataset (and excluding SVL), PC1 explains 26.2\% and PC2 $16.8 \%$ of the variation (Fig. 3C, S6C). The log-transformed PCA shows more evidence of clustering by lineage than does the size-corrected PCA. Together these observations point to a 359 high similarity in shape, relative to divergence in body size. For $C$. triacantha, similar results were obtained (Fig. 3B, S6B). The proportions of variance explained for log transformed analysis were $\mathrm{PC} 1=74.3 \%$ and $\mathrm{PC} 2=7.2 \%$; whereas, for the size corrected analysis, $\mathrm{PC} 1=$ $19.5 \%$ and $\mathrm{PC} 2=15.4 \%$ (Fig. 3D, S6D). confirmed that size $(\operatorname{logSVL})$ differs between lineages in each species $\left(p=1.05 \times 10^{-6}\right.$ in $C$. johnstonei; $p=6.96 \times 10^{-3}$ in $C$. triacantha $)$. For size-corrected data, head depth $\left(p=1.36 \times 10^{-3}\right)$, 367 nasal separation $\left(p=9.02 \times 10^{-3}\right)$, forelimb $\left(p=7.89 \times 10^{-3}\right)$, and hindlimb $\left(p=2.55 \times 10^{-2}\right)$ are 368 important traits in distinguishing Johnstonei A from Johnstonei B; and head length $\left(p=3.30 \times 10^{-}\right.$ 
$369^{4}$ ) and ear to eye distance $\left(p=2.73 \times 10^{-2}\right)$ for distinguishing Triacantha A from Triacantha B (Fig.

370 4). The significant non-normal variables within $C$. triacantha were confirmed with significant 371 non-parametric test (Table S5).

372 The analysis of meristic data was based on three relevant characters (number of ear lobules,

373 lamellae number under the $3^{\text {rd }}$ finger and under the $4^{\text {th }}$ toe) due to little or no variation in the

374 other traits. Each of the three analysed characters was significantly different between Johnstonei

375 A and B, but only ear lobule number showed a significant difference between Triacantha A and

376 B (Fig.4, Table S6).

377 The prediction capacity of significant morphological data was investigated with a linear

378 discriminant analysis (LDA) and a Random Forest analysis (RF). Jackknife results provided

$37985.87 \%$ accuracy for differentiating C. johnstonei lineages based on log-transformed

380 morphological measurements (to include SVL as a variable) and $72.34 \%$ for C. triacantha

381 lineages. While the accuracy estimated with a RF analysis was $81.52 \%$ for C. johnstonei and

$382 \quad 68.09 \%$ for C. triacantha.

383 The summary of each measured trait can be found in supplementary Table S7.

384

385 Taxonomic assessment and species description

386 Considering the congruence across multiple genetic delimitation methods and of these

387 with significant morphological divergence among lineages, we provide sufficient evidence for

388 four species, two species within Carlia johnstonei and two species within C. triacantha. Within

389 C. johnstonei, Johnstonei A is the nominal C. johnstonei species based on a holotype from the

390 Mitchell Plateau, a region in which extensive sampling has shown that only Johnstonei A occurs.

391 For C. triacantha the holotype specimen is from Adelaide River, Northern Territory, a site close 
$392(\sim 15 \mathrm{~km})$ to Triacantha A samples from Litchfield National Park (NTM R22162) - hence we

393 suggest that Triacantha A should retain the species name. Accordingly, we here describe two

394 new species - Johnstonei B as Carlia insularis sp. nov. and Triacantha B as Carlia isostriacantha

395 sp. nov. In the following we provide diagnoses for the four species. Simple genetic diagnostics

396 (mtDNA diagnostic SNPs; Table 2) are robust. For morphology alone, single traits mostly have

397 overlapping ranges, but in combination with each other and geography, should be practical in the 398 field.

399

400 Carlia johnstonei Storr, 1974 Records of the Western Australian Museum, Vol. 3, 151-165

401 Rough brown rainbow-skink

402 Holotype. WAM R43170, from Mitchell Plateau, Western Australia, in -14.866667 125.833333.

403 Diagnosis. Dark blackish Carlia morphologically distinguishable from geographically

404 overlapping species with a combination of mid-dorsal scales bicarinate (two keels), more

405 numerous supraciliares (usually 7 vs. 6 -C. amax, C. munda, C. rufilatus, C. isostriacantha sp.

406 nov., or $5-$ C. gracilis), larger ear aperture with numerous sharply pointed lobules (mean of 10

407 lobules), but typically less than in C. insularis sp. nov. (mean of 13 lobules). Further

408 distinguished from the latter by smaller body size (mean $36.39 \mathrm{~mm}$ vs. $41.83 \mathrm{~mm}$ ), reduced head

409 depth (mean $3.59 \mathrm{~mm}$ vs. $4.48 \mathrm{~mm}$ ), shorter limbs (forelimbs $9.51 \mathrm{~mm}$ vs. 11.45 and hindlimbs

$41014.82 \mathrm{~mm}$ vs. $17.77 \mathrm{~mm}$ ) and less lamellae under longest finger (mean $16.75 \mathrm{~mm}$ vs. $19.69 \mathrm{~mm}$ )

411 and toe (mean $22.83 \mathrm{~mm}$ vs. $26.31 \mathrm{~mm}$ ).

412 Description. Snout-vent length $(\mathrm{mm}): 21.84-43.49(\mathrm{~N}=66$, mean 36.39). Tail: $27.1-61.28(\mathrm{~N}$

$413=26$, mean 46.04). Most specimens with separated prefrontal scales (93\%) by an average of 0.32

$414 \mathrm{~mm}(\mathrm{~N}=50,0.05-0.64)$. Ear aperture smaller $(\mathrm{N}=62$, mean 1.01, $0.50-1.44)$, than palpebral 
$415 \operatorname{disc}(\mathrm{N}=62$, mean $1.31,1.05-1.59)$, with many small lobules (mean 10, 5 - 16). Lamellae 416 under third finger $9-20(\mathrm{~N}=63$ mean 16.75), fourth toe $15-27(\mathrm{~N}=63$ mean 22.83) (Table

417 S7). Most specimens are dorsally dark brown and ventrally yellow but with either a bright or 418 dark blue gular.

419 Distribution. Distributed across the sub-humid area in the Kimberley, from the northeast

420 Berkeley River region, to the southwest King Leopold Ranges (Fig. 1). Present in humid islands 421 in the Kimberley, mostly the northern islands and those closer to the mainland. In drier

422 environments, this species tends to be more restricted to mesic microhabitats in rocky gorges 423 (Russell Barrett pers. comm.).

424 Remarks. The previous described paratype from East Montalivet Island (WAM R41462) in Storr 425 (1974) by geographic location should belong to C. insularis sp. nov.

426

427 Carlia insularis sp. nov. (Figs. S7A, S8A, C and S9A) urn:1sid:zoobank.org:act:F058DFD2428 799C-4242-8926-9F59AEC6FD44

429 Kimberley islands rainbow-skink

430 Holotype. WAM R158646, from North Maret island, Western Australia, in -14.3983 124.97750.

431 Specimen collected in 2004 by Richard How (Fig. S7A).

432 Paratypes. Fenelon Island: WAM R117708, WAM R117709, WAM R117710; Corneille Island:

433 WAM R117967; West Montalivet Island: WAM R158562, WAM R158571; Don Island: WAM

434 R158610; North Maret Island: WAM R158647 (Table S1, Fig. S8A, C).

435 Etymology. Insularis is derived from the Latin word insular, for island, since this species is 436 restricted to islands.

437 Diagnosis. Morphologically similar to C. johnstonei and distinguished from this species by the 
438 presence of mid-dorsal body scales with a mix of two or three keels (Fig. 5), whereas $C$.

439 johnstonei always has two keels. As mentioned previously, it is also distinguished from $C$.

440 johnstonei by longer body size, higher relative head depth, longer relative limb length, more

441 sharp lobules in the ear aperture (mean values of 13 vs. 10; Fig. 5) and more lamellae under

442 longest finger and toe (average 3 more). Prefrontal scales are either narrowly separated or in

443 contact, while $C$. johnstonei often has more widely separated prefrontals. From a genetic

444 perspective, four sites that change amino acids in the mtDNA ND4 sequence reliably distinguish

445 Carlia johnstonei and Carlia insularis sp. nov. (Table 2). Geographically distinct from $C$.

446 johnstonei in some of the most outer islands of the Bonaparte Archipelago (see bellow).

447 Comparison with congeners. Distinguished from remaining Australian Carlia species by a

448 reduced upper preocular and well separated from posterior margin of second loreal scale (Hoskin

449 \& Couper, 2012); a distinct interparietal, usually seven supraciliaries, prefrontals usually

450 separated; at least 34 mid-body scale rows, that are dorsally 6-sided, each scale with an angular

451 free edge and strongly bicarinate, with the keels aligned to form continuous longitudinal lines;

452 ear-opening surrounded by many small and pointed lobules (Cogger, 2014). It is endemic to

453 Kimberley islands where $C$. johnstonei and $C$. isostriacantha sp. nov. also occur at a regional

454 scale. See diagnosis to distinguish from C. johnstonei; and distinguishable from $C$.

455 isostriacantha sp. nov. by the presence of two keeled-scales and usually seven supraciliaries

456 instead of six.

457 Description of holotype. Individual with $42.01 \mathrm{~mm}$ as SVL, tail $69.33 \mathrm{~mm}$, axilla-groin length

$45819.71 \mathrm{~mm}$, head length $8.86 \mathrm{~mm}$, head width $6.29 \mathrm{~mm}$, head depth $3.85 \mathrm{~mm}$, forelimb 12.47 and

459 hindlimb $17.42 \mathrm{~mm}$. Body with keeled dorsal scales, mostly two keels but some scales with

460 three. Six supraciliares, seven supralabials, six infralabials, 19 subdigital lamellae in $3^{\text {rd }}$ finger, 
46126 subdigital lamellae in $4^{\text {th }}$ toe. Circular ear not smaller $(1.37 \mathrm{~mm})$ than palpebral disc $(1.19$

$462 \mathrm{~mm})$ with 12 sharp ear lobules. Prefrontals narrowly separately and nasals widely spaced (2.56

$463 \mathrm{~mm})$. Midbody scale rows 37, 43 vertebral scales and 62 ventral scales.

464 Description. Snout-vent length $(\mathrm{mm}): 27.93-51.44(\mathrm{~N}=35$, mean 41.83). Tail: $29.05-69.98(\mathrm{~N}$

$465=18$, mean 51.02). Most specimens with separated prefrontal scales (62\%) by an average of 0.18

$466 \mathrm{~mm}(\mathrm{~N}=21,0.02-0.54)$. Ear aperture smaller $(\mathrm{N}=32$, mean $1.27,0.85-2.16)$, than palpebral

$467 \operatorname{disc}(\mathrm{N}=32$, mean $1.44,1.04-2.13)$, with many small lobules (up to 18). Lamelae under third

468 finger $17-23(\mathrm{~N}=35$ mean 19.69), fourth toe $21-30(\mathrm{~N}=35$ mean 26.31) (Table S7).

469 Laterally and dorsally blackish brown while ventrally yellowish with sometimes a bright blue or

470 a dark blue gular (Fig. S8C), where in breeding males (Fig. S9A) lateral midbody has a light

471 brown almost orange colour.

472 Distribution. Across the northwest and outer islands of the Bonaparte Archipelago (northern

473 Kimberley islands in Western Australia) with confirmed occurrence on the Fenelon, Corneille,

474 East Montalivet, West Montalivet, Don, Berthier, North Maret and South Maret islands.

475 Remarks. Despite extensive sampling, there are no records of $C$. insularis sp. nov. and $C$.

476 johnstonei occurring on the same islands. All islands where the former species is confirmed are

477 either laterite or volcanic islands, whereas C. johnstonei also occurs in sandstone islands (How et

478 al., 2006). The individuals of $C$. insularis sp. nov. were collected in vine thicket and deciduous

479 vine forest habitats (Richard How; pers. comm.). Despite Descartes island being relatively close

480 to Fenelon and Corneille islands, only C. johnstonei was confirmed on this island.

481

482 Carlia triacantha Mitchell, 1953, Records of the South Australian Museum, Vol. 11, 75-90

483 Desert rainbow-skink 
484 Holotype. SAM R2697, from Adelaide River, Northern Territory, in -13.183 131.1.

485 Diagnosis. Species morphologically distinguished from congeners by having three strong keels

486 in scales, prefrontals more often in contact or very narrowly separated and usually six

487 supraciliaries. Although more work is still needed to find unambiguously diagnostic traits

488 between this species and C. isostricantha sp. nov., C. triacantha are mostly smaller (mean 36.55

$489 \mathrm{~mm}$ vs. $40.07 \mathrm{~mm}$ ), with shorter relative head length (mean $7.24 \mathrm{~mm}$ vs. $8.25 \mathrm{~mm}$ ) and fewer ear

490 lobules (usually 6 vs. 9, Fig. 5B). Geographically diagnosis from C. isostricantha sp. nov.,

491 possible in the centre of Australia, particularly Pilbara and Macdonald ranges region.

492 Description. Snout-vent length $(\mathrm{mm}): 23.78-44.98(\mathrm{~N}=35$, mean 36.55). Tail: $38.48-75.90(\mathrm{~N}$

$493=17$, mean 60.80). Prefrontal in contact (63\%) while the rest with separated prefrontals $(\mathrm{N}=11)$

494 by an average of $0.26 \mathrm{~mm}(0.03-1.81)$. Ear aperture smaller $(\mathrm{N}=30$, mean $1.13,0.64-1.73)$,

495 than palpebral disc $(\mathrm{N}=30$, mean $1.41,0.99-1.71)$, with often one larger anterior lobule and

496 several small (up to 7). Lamellae under third finger $16-22(\mathrm{~N}=30$ mean 18.83 ), fourth toe $23-$

$49728(\mathrm{~N}=29$ mean 24.83) (Table S7). Dorsally brown and ventrally yellow blueish with

498 sometimes whitish line under eye.

499 Distribution. Widely distributed from Pilbara in Western Australia to Northern Territory (Fig. 1).

500 However, more sampling and genetic analyses are needed to investigate whether this species is

501 continuously distributed from the mesic Top End to arid central Australia or if the central Top

502 End is only occupied by C. isostriacantha sp. nov.

503

504 Carlia isostriacantha sp. nov. (Fig. S7B, S8B, D and S9B)

505 urn:1sid:zoobank.org:act:EB2E9D69-8E1F-466D-8441-E2E4DD59F96E

506 Monsoonal three-keeled rainbow-skink 
507 Holotype. WAM R171420, from Prince Regent Nature Reserve, Western Australia, in -15.98972 508 125.32944. Specimen collected in 2010 by Paul Doughty (Fig. S7B).

509 Paratypes. WAM R168173 (Boongaree Island), WAM R168675 (Katers Island), WAM R171211

510 (Darcy Island), WAM R171905 (Wargul Wargul Island), WAM R171906 (Molema Island),

511 WAM R171908 (Sunday Island), WAM R171909 (Balami ridge), WAM R171916 (Lachlan

512 Island), WAM R171921 (Storr Island), WAM R171933 (Balami ridge) (Table S1, Fig. S8B, D).

513 Etymology. Isostriacantha is derived from equal in greek (isos) with triacantha, (three spines,

514 referring to the three keels in scales) due to the difficulty of morphologically distinguishing from

515 its sister species C. triacantha.

516 Diagnosis. As similar to C. triacantha, this species is morphologically distinguished from other

517 Carlia species by having three strong keels in scales, prefrontals more often in contact or very

518 narrowly separated and usually six supraciliaries. As above-mentioned, in contrast with it closest

519 relative, $C$. triacantha, this species has longer body size, a relatively longer head and tends to

520 have more ear lobules, on average nine very small lobules (Fig. 4 and 5, Table S7). Another

521 possible trait to distinguish between these species is a white line that begins posterior to each

522 hind limb and can extend to midway through the tail (Fig. S9B). This trait is more evident in

523 freshly caught individuals, or photographs of them, than in long preserved specimens and needs

524 to be further tested through more observations on genetically typed individuals. Genetically

525 diagnosed from C. triacantha, by three ND4 mtDNA sites (Table 2) and geographically by

526 occurring in the Kimberley, although geographic diagnoses in Northern Territory requires further

527 work.

528 Comparison with congeners. This species can be separated from most Australian Carlia species

529 by an upper preocular reduced and well separated from posterior margin of second loreal scale 
530 (Hoskin \& Couper, 2012); a distinct interparietal, with usually six supraciliaries, prefrontals

531 usually in contact or narrowly separated; 28-36 rows of mid-body scales, that are dorsally 6-

532 sided triscupid, each usually with an angular free edge and strongly keeled; often one larger

533 anterior lobule with many small lobules in a round ear-opening that is smaller than palpebral

534 disc, while the palpebral disc occupies much more than half of lower eyelid (Cogger 2014).

535 Specifically with potentially sympatric species, C. johnstonei, C. amax, C. rufilatus, C. gracilis

536 and C. munda, this species can be identified by the presence of three strong keels in scales,

537 prefrontals usually in contact, six supraciliaries and absence of white lateral line anterior to the

538 forelimbs. To distinguish from its sister species, C. triacantha, see Diagnosis above.

539 Description of holotype. Male individual with $43.22 \mathrm{~mm}$ as SVL, tail $63 \mathrm{~mm}$, axilla-groin length

$54020.06 \mathrm{~mm}$, head length $8.79 \mathrm{~mm}$, head width $6.57 \mathrm{~mm}$, head depth $3.83 \mathrm{~mm}$, forelimb $13.06 \mathrm{~mm}$

541 and hindlimb $19.34 \mathrm{~mm}$. Body with three keeled dorsal scales. Six supraciliares, seven

542 supralabials, six infralabials, 17 subdigital lamellae in third finger, 23 subdigital lamellae in

543 fourth toe. Horizontal ear wider $(1.83 \mathrm{~mm})$ than palpebral disc $(1.57 \mathrm{~mm})$ with 13 small sharp

544 ear lobules (one anterior larger). Prefrontals in contact and nasals widely spaced (2.34 $\mathrm{mm})$.

545 Midbody scale rows 35, 38 vertebral scales and 52 ventral scales.

546 Description. Snout-vent length (mm): 24.72 - $49.12(\mathrm{~N}=68$, mean 40.07). Tail: $29.1-86.68(\mathrm{~N}$

$547=39$, mean 61.55). Prefrontal in contact $(73 \%)$ while the rest with separated prefrontals $(\mathrm{N}=19)$

548 by an average of $0.12 \mathrm{~mm}(0.01-0.37)$. Ear aperture smaller $(\mathrm{N}=67$, mean $1.33,0.69-1.96)$,

549 than palpebral disc $(\mathrm{N}=67$, mean 1.46, $0.92-1.81)$, with often one larger anterior lobule, many

550 small (up to 13) and sometimes one superior. Lamelae under third finger $11-24(\mathrm{~N}=62$ mean

551 19.27), fourth toe $18-30(\mathrm{~N}=62$ mean 24.82) (Table S7). Dorsally brown and ventrally yellow

552 blueish, with a light line under eye to ear, and often with a very light whitish line in the back of 
553 hindlimbs to tail if not regrown (Fig. S9B).

554 Distribution. Widespread across the Kimberley and adjacent (mostly southern Kimberley)

555 islands in Western Australia, with isolated records in the western Gulf region, spanning the

556 border of the Northern Territory and Queenland (Fig. 1).

557 Remarks. Afonso Silva et al. (2017) found one genetically discordant sample with mtDNA of $C$.

558 isostriacantha $\mathrm{sp}$. nov. and nuclear of C. triacantha from the Victoria River region

559 (ABTC61613, Table S1). This suggests a need for further regional surveys and genetic studies,

560 particularly in the Northern Territory where only a few specimens with tissues were detected, to

561 define the boundaries of both species, at geographical and morphological level.

562

563 Discussion

564 We used extensive genetic and morphological data to identify two new species of

565 Rainbow skinks, Carlia insularis sp. nov. (Johnstonei B lineage) and Carlia isostriacantha sp.

566 nov., (Triacantha B lineage), in an understudied region of Australia, the Kimberley. We also

567 redefined diagnoses and geographic distributions of Carlia johnstonei and C. triacantha. Our

568 work takes advantage of recent progress in techniques for obtaining large-scale sequence data

569 and in methods for species delimitation, as part of a broader integrative taxonomic approach.

570 These advances are particularly important for identifying cryptic species, such as those described

571 here, where morphological evidence alone is often insufficient for reliable species identification.

572

573 Evidence for new cryptic species

574 A previous phylogeographic study with $>2000$ loci Afonso Silva et al. (2017) revealed two 575 new candidates species in the Carlia genus. The current work confirms these are new species 
576 using three robust hypothesis-driven validation methods based on several independent sets of

577 genes from the larger exon dataset. The use of multiple different methods provides a robust test

578 for the previous discovery in Afonso Silva et al. (2017), and further validates the proposed

579 species delimitation.

580 Although the existence of $C$. insularis sp. nov. and C. isostriacantha sp. nov. is well

581 supported in the genetic data, distinguishing these species morphologically is more difficult due

582 to their cryptic nature. The genus Carlia generally has few diagnostic taxonomic characters that

583 allow for the separation of species using morphology. Even for C. johnstonei and C. triacantha

584 as currently recognised, there are only a few morphological characters that effectively

585 distinguish between these species, mainly the number of keels on the dorsal scales and the

586 arrangement of ear lobules (Storr, 1974). However, morphological measurements broadly

587 overlap between both $C$. johnstonei and C. triacantha lineages. Despite these issues, we were

588 able to find statistically significant differences in morphology across both measurements and

589 meristic data, supporting the presence of these lineages as different species.

590 Differences in body size, head and limbs traits as well as ear lobule numbers help in

591 distinguishing the lineages. Morphological variation across each pair of taxa is strongly affected

592 by body size (SVL), with the newly described species being larger than their respective sister

593 taxa. The same is observed for the other significant traits, even after accounting for size.

594 Although for both species, there are some overlap between morphological groups, there was

595 more morphological similarity between the $C$. triacantha lineages than between $C$. johnstonei

596 lineages (Fig. 3), likely reflecting the shallower divergence seen within C. triacantha.

597 Though we were able to identify a few distinct morphological traits, using morphology

598 alone to identify individuals will remain a challenge without a reference to geography. For the 
599 two lineages within C. triacantha, even geography is a poor guide for the central Northern

600 Territory region. Therefore, for more reliable diagnosis, we follow the suggestion of Renner

601 (2016) and include a set of diagnostic mtDNA SNPs to distinguish between C. johnstonei and $C$.

602 insularis sp. nov., and between $C$. triacantha and $C$. isostriacantha sp. nov. These SNPs can be

603 easily assessed by cheaper Sanger sequencing of the mtDNA gene ND4 (primers and protocol in

604 Afonso Silva et al., 2017).

605

606 Biodiversity significance of the two new species

607 C. insularis sp. nov. is an important addition to the known biodiversity of the Kimberley

608 islands. This region has recently been the focus of several studies that have documented unique

609 biodiversity communities, namely in terms of vegetation (Lyons et al., 2012), avifauna (Pearson

610 \& Caton, 2013) and herpetofauna (Doughty et al., 2012; Palmer et al., 2013). Studies to

611 understand the biodiversity value in this region are also of importance to conservation, as this

612 area is being considered as a biodiversity refuge for fauna vulnerable to the invasive Cane Toad

613 (Palmer et al., 2013). Although the west Kimberley region has several endemic species, only a

614 few are endemic just to the islands, namely a blindsnake (Ellis, 2016) and several land snails

615 (Criscione \& Köhler, 2013, 2014), making the discovery of C. insularis sp. nov. very significant.

616 But more island-endemics reptiles are expected to be described, since Palmer et al. (2013)

617 suggested the occurrence of a few potential new species (including samples that correspond to $C$.

618 insularis sp. nov.) that have not yet been described.

619 Although our genetic data allows us to describe C. isostriacantha sp. nov. as a new

620 species, further collecting and analyses are needed across central Northern Territory for this and

621 other taxa (also suggested in Rosauer et al., 2016). Specifically, there is a need to identify the 
622 geographic distributions of $C$. triacantha sensu stricto and C. isostriacantha sp. nov., as well as

623 to examine morphological divergence in this poorly sampled region. In a group of Ctenotus

624 skinks, Rabosky et al. (2014) highlight how intraspecific morphological variability and

625 geographic sampling gaps caused an inadequate understanding of biological diversity. As with

626 Ctenotus, we suspect that many other species in the Carlia genus may yet require taxonomic

627 revision. Potter et al. (2016) have also suggested unknown lineage diversity in another Carlia

628 species in the Australian Monsoonal Tropics, which may lead to the description of additional

629 Carlia species, particularly on the islands off the northeast Top End.

630

631

Advantages and issues of using MSC methods

632

A key element of our analysis was the use of multispecies coalescent (MSC) methods,

633 including pioneering the application of StarBEAST2 to Bayes Factor species delimitation (BFD).

634 MSC models are a robust approach that better describes species formation by considering

635 coalescent processes; however, methods based on the MSC are typically computationally

636 intensive. To surpass this limitation, we subsetted independent smaller sets of loci from around

6372,300 loci, which also has the advantage of producing multiple replicate results that may be

638 compared to confirm that estimated parameter values are robust to the choice of loci.

639

BFD using SNAPP and StarBEAST2 requires sampling from different power posteriors,

640 including sampling purely from the prior. We found that convergence was difficult to achieve for

641 our data set when BFD StarBEAST2 was used to sample from the prior with more than 20 loci.

642 Despite this limitation, BFD StarBEAST2 has advantages over existing methods for species

643 delimitation. Compared to SNAPP which requires unlinked SNPs, StarBEAST2 can extract

644 much more information from each locus. Compared to BPP, StarBEAST2 has many more 
645 options for substitution models, population size models, and relaxed clock models.

646

\section{Conclusions}

648 As Oliver, Keogh \& Moritz (2015) express, most genetically divergent lineages within 649 species remain invisible to other scientific work, like conservation assessments and management 650 planning. This reinforces the need to evaluate whether genetically distinct lineages within 651 species should be formally described. Here we validate and describe two new species of rainbow 652 skinks in the northwest of Australia, a highly biodiverse region of Australia that is still relatively 653 understudied. Using an integrative taxonomic approach, we employ three MSC methods, 654 including the application of a new approach to delimit species, as well as integrating 655 morphological data to provide strong evidence for these two new species. This work brings the 656 number of Australian Carlia to 26 species. However, further such work is needed across the 657 Australian Monsoonal Tropics, since deeply divergent lineages within species of lizards are the 658 norm in this region.

659

\section{Acknowledgements}

661

We thank the Museum and Art Gallery of the Northern Territory, Museum Victoria,

662 South Australia Museum and Western Australia Museum for specimens, in particular to Ryan

663 Ellis for his assistance. We are also grateful to members of the Moritz lab for ongoing

664 discussions and comments relating to this study, and in particular to Mozes Blom, Joshua

665 Peñalba, Rebecca Laver, Sally Potter, as well to Emma Sherratt, Liam Bailey and Thomas

666 Merkling for advice on analysis and comments on the manuscript. We are also grateful to

667 Fabricius Domingos and an anonymous reviewer for helpful comments. We acknowledge credit 
668 and thank to Erin Walsh, Damien Esquerré, Russell Barrett and Mark Allen for illustrations and 669 photos.

670

\section{References}

672 Abràmoff MD., Magalhães PJ., Ram SJ. 2004. Image processing with ImageJ. Biophotonics 673 international 11:36-42.

674 Afonso Silva AC., Bragg JG., Potter S., Fernandes C., Coelho MM., Moritz C. 2017. Tropical 675 specialist vs. climate generalist: Diversification and demographic history of sister species of 676 Carlia skinks from northwestern Australia. Molecular Ecology 0:1-14. DOI:

$677 \quad 10.1111 /$ mec. 14185 .

678 Andersen AN., Bocciarelli D., Fairman R., Radford IJ. 2014. Conservation status of ants in an 679 iconic region of monsoonal Australia: levels of endemism and responses to fire in the 680 eastern Kimberley. Journal of Insect Conservation 18:137-146. DOI: 10.1007/s10841-014$6819624-x$.

682 Bickford D., Lohman DJ., Sodhi NS., Ng PKL., Meier R., Winker K., Ingram KK., Das I. 2007.

683 Cryptic species as a window on diversity and conservation. Trends in Ecology and 684 Evolution 22:148-155. DOI: 10.1016/j.tree.2006.11.004.

685 Blom MPK. 2015. EAPhy: A flexible tool for high-throughput quality filtering of exon686 alignments and data processing for phylogenetic methods. PLOS Currents Tree of Life 1. 687 DOI: doi:10.1371/ currents.tol. 75134257bd389c04bc1d26d42aa9089f.

688 Bragg JG., Potter S., Bi K., Moritz C. 2015. Exon capture phylogenomics: efficacy across scales 689 of divergence. Molecular Ecology Resources 16:1059-1068. DOI: 10.1111/1755$690 \quad 0998.12449$. 
691 Bryant D., Bouckaert R., Felsenstein J., Rosenberg NA., RoyChoudhury A. 2012. Inferring 692 species trees directly from biallelic genetic markers: bypassing gene trees in a full $693 \quad$ coalescent analysis. Molecular Biology and Evolution 29:1917-1932. DOI: $694 \quad 10.1093 / \mathrm{molbev} / \mathrm{mss} 086$.

695 Carstens BC., Pelletier TA., Reid NM., Satler JD. 2013. How to fail at species delimitation. 696 Molecular Ecology 22:4369-4383. DOI: 10.1111/mec.12413.

697 Cogger H. 2014. Reptiles and amphibians of Australia. New Holland, Sydney.

698 Criscione F., Köhler F. 2013. Six new species of Australocosmica Köhler, 2011 from the 699 Kimberley Islands, Western Australia (Mollusca: Pulmonata: Camaenidae). Zootaxa $700 \quad 3608: 101-15$. DOI: 10.11646/zootaxa.3608.2.1.

701 Criscione F., Köhler F. 2014. Molecular phylogeny and taxonomic revision of the genera 702 Baudinella Thiele, 1931, Retroterra Solem, 1985 and Molema Köhler, 2011 endemic to the 703 coastal Kimberley, Western Australia (Gastropoda, Camaenidae). Journal of Zoological $704 \quad$ Systematics and Evolutionary Research 52:273-284. DOI: 10.1111/jzs.12065.

705 Darriba D., Taboada GL., Doallo R., Posada D. 2012. jModelTest 2: more models, new 706 heuristics and parallel computing. Nature Methods 9:772. DOI: 10.1038/nmeth.2109.

707 Degnan JH., DeGiorgio M., Bryant D., Rosenberg NA. 2009. Properties of Consensus Methods 708 for Inferring Species Trees from Gene Trees. Systematic Biology 58:35-54. DOI: $709 \quad 10.1093 /$ sysbio/syp008.

710 Dolman G., Hugall AF. 2008. Combined mitochondrial and nuclear data enhance resolution of a 711 rapid radiation of Australian rainbow skinks (Scincidae: Carlia). Molecular Phylogenetics 712 and Evolution 49:782-94. DOI: 10.1016/j.ympev.2008.09.021.

713 Doughty P., Palmer R., Cowan M., Pearson DJ. 2012. Biogeographic patterns of frogs of the 
714 Kimberley islands, Western Australia. Records of the Western Australian Museum

715 Supplement 81:109-124. DOI: 10.18195/issn.0313-122x.81.2012.109-124.

716 Drummond AJ., Rambaut A. 2007. BEAST: Bayesian evolutionary analysis by sampling trees.

717 BMC Evolutionary Biology 7:214. DOI: 10.1186/1471-2148-7-214.

718 Edwards S V., Xi Z., Janke A., Faircloth BC., McCormack JE., Glenn TC., Zhong B., Wu S.,

719 Lemmon EM., Lemmon AR., Leaché AD., Liu L., Davis CC. 2016. Implementing and

720 testing the multispecies coalescent model: a valuable paradigm for phylogenomics.

721 Molecular Phylogenetics and Evolution 94:447-462. DOI: 10.1016/j.ympev.2015.10.027.

722 Ellis RJ. 2016. A New Species of Blindsnake (Scolecophidia: Typhlopidae: Anilios) from the

723 Kimberley Region of Western Australia. Herpetologica 72:271-278. DOI:

$724 \quad 10.1655 /$ Herpetologica-D-16-00007.1.

725 Ence DD., Carstens BC. 2011. SpedeSTEM: a rapid and accurate method for species

726 delimitation. Molecular Ecology Resources 11:473-80. DOI: 10.1111/j.1755-

$727 \quad$ 0998.2010.02947.x.

728 Fujita MK., Leaché AD., Burbrink FT., McGuire JA., Moritz C. 2012. Coalescent-based species

729 delimitation in an integrative taxonomy. Trends in ecology \& evolution 27:480-8. DOI:

$730 \quad 10.1016 / j$. tree.2012.04.012.

731 Grummer JA., Bryson RW., Reeder TW. 2014. Species delimitation using Bayes Factors:

732 simulations and application to the Sceloporus scalaris species group (Squamata:

733 Phrynosomatidae). Systematic Biology 63:119-133. DOI: 10.1093/sysbio/syt069.

734 Guindon S., Gascuel O., Rannala B. 2003. A Simple, fast, and accurate algorithm to estimate

735 large phylogenies by maximum likelihood. Systematic Biology 52:696. DOI:

$736 \quad 10.1080 / 10635150390235520$. 
737 Hedin M., Carlson D., Coyle F. 2015. Sky island diversification meets the multispecies

738 coalescent - divergence in the spruce-fir moss spider (Microhexura montivaga, Araneae,

739 Mygalomorphae) on the highest peaks of southern Appalachia. Molecular Ecology

$740 \quad 24: 3467-3484$. DOI: $10.1111 / \mathrm{mec} .13248$.

741 Hoskin CJ. 2014. A new skink (Scincidae: Carlia) from the rainforest uplands of Cape Melville, 742 north-east Australia. Zootaxa 3869:224-236. DOI: 10.11646/zootaxa.3869.3.2.

743 Hoskin CJ., Couper PJ. 2012. Description of two new Carlia species (Reptilia: Scincidae) from north-east Australia, elevation of Carlia pectoralis inconnexa Ingram \& Covacevich 1989 to full species status, and redescription of Carlia pectoralis (de Vis 1884). Zootaxa:1-28.

746

747

748

749

750

751

752

753

754

755

756

757

758

759

How R., Schmitt L., Teale R., Cowan M. 2006. Appraising vertebrate diversity on Bonaparte Islands, Kimberley, Western Australia. The Western Australian Naturalist 25:92-110.

Isaac NJB., Mallet J., Mace GM. 2004. Taxonomic inflation: its influence on macroecology and conservation. Trends in Ecology \& Evolution 19:464-469. DOI: 10.1016/j.tree.2004.06.004.

Kass RE., Raftery AE. 1995. Bayes Factors. Journal of the American Statistical Association 90:773-795. DOI: 10.1080/01621459.1995.10476572.

Kearse M., Moir R., Wilson A., Stones-Havas S., Cheung M., Sturrock S., Buxton S., Cooper A., Markowitz S., Duran C., Thierer T., Ashton B., Meintjes P., Drummond A. 2012. Geneious Basic: an integrated and extendable desktop software platform for the organization and analysis of sequence data. Bioinformatics 28:1647-9. DOI: 10.1093/bioinformatics/bts199.

Köhler F. 2011. Descriptions of new species of the diverse and endemic land snail Amplirhagada iredale, 1933 from rainforest patches across the Kimberley, Western Australia (Pulmonata: Camaenidae). Records of the Australian Museum 63:167-202. DOI: 10.3853/j.00671975.63.2011.1581. 
760 Komsta L. 2011. Outliers: Tests for outliers. R package version 0.14. https://CRAN.R-

$761 \quad$ project.org/package $=$ outliers.

762 Korkmaz S., Goksuluk D., Zararsiz G. 2014. MVN: An R package for assessing multivariate 763 normality. The R Journal 6:151-162.

764 Lanier HC., Knowles LL. 2012. Is Recombination a problem for species-tree analyses?

$765 \quad$ Systematic Biology 61:691. DOI: 10.1093/sysbio/syr128.

766 Leaché AD., Fujita MK. 2010. Bayesian species delimitation in West African forest geckos

767 (Hemidactylus fasciatus). Proceedings of the Royal Society of London B: Biological

768 Sciences 277:3071-3077. DOI: 10.1098/rspb.2010.0662.

769 Leaché AD., Fujita MK., Minin VN., Bouckaert RR. 2014. Species delimitation using genome770 wide SNP data. Systematic Biology 63:534-42. DOI: 10.1093/sysbio/syu018.

771 Liaw A., Wiener M. 2002. Classification and regression by randomForest. R News 2:18-22.

772 Lyons MN., Keighery GJ., Gibson LA., Handasyde T. 2012. Flora and vegetation communities 773 of selected islands off the Kimberley coast of Western Australia. Records of the Western 774 Australian Museum Supplement 81:205-244. DOI: 10.18195/issn.0313-122x.81.2014.205775244.

776 McKenna A., Hanna M., Banks E., Sivachenko A., Cibulskis K., Kernytsky A., Garimella K., 777 Altshuler D., Gabriel S., Daly M., DePristo MA. 2010. The Genome Analysis Toolkit: a 778 MapReduce framework for analyzing next-generation DNA sequencing data. Genome 779 Research 20:1297-303. DOI: 10.1101/gr.107524.110.

780 Mitchell FJ. 1953. A brief revision of the four-fingered members of the genus Leiolopisma. 781 Records of the South Australian Museum:75-90.

782 Ogilvie HA., Bouckaert R., Drummond AJ. 2017. StarBEAST2 brings faster species tree 
783

784

785

786

787

788

789

790

791

792

793

794

795

796

797

798

799

800

801

802

803

804

805

inference and accurate estimates of substitution rates. Molecular Biology and Evolution. DOI: $10.1093 / \mathrm{molbev} / \mathrm{msx} 126$.

Oliver PM., Bourke G., Pratt RC., Doughty P., Moritz C. 2016. Systematics of small Gehyra (Squamata: Gekkonidae) of the southern Kimberley, Western Australia: Redescription of G. kimberleyi Börner \& Schüttler, 1983 and description of a new restricted range species. Zootaxa 4107:49-64. DOI: 10.11646/zootaxa.4107.1.2.

Oliver P., Keogh JS., Moritz C. 2015. New approaches to cataloguing and understanding evolutionary diversity: a perspective from Australian herpetology. Australian Journal of Zoology 62:417-430. DOI: 10.1071/ZO14091.

Oliver PM., Laver RJ., Melville J., Doughty P. 2014. A new species of Velvet Gecko (Oedura: Diplodactylidae) from the limestone ranges of the southern Kimberley, Western Australia. Zootaxa 3873:49-61. DOI: 10.11646/zootaxa.3873.1.4

Padial J., Miralles A., Riva ID la., Vences M. 2010. The integrative future of taxonomy. Frontiers in Zoology 7:1-14. DOI: 10.1186/1742-9994-7-16

Palmer R., Pearson DJ., Cowan MA., Doughty P. 2013. Islands and scales: a biogeographic survey of reptiles on Kimberley islands, Western Australia. Records of the Western Australian Museum Supplement 81:183-204. DOI: 10.18195/issn.0313-122x.81.2013.183204

Park J., Koo K-S., Kim I-H., Park D. 2016. Complete mitochondrial genomes of Scincella vandenburghi and S. huanrenensis (Squamata: Scincidae). Mitochondrial DNA Part B 1:237-238. DOI: 10.1080/23802359.2016.1156490.

Pearson DJ., Caton W. 2013. The avifauna of larger islands along the Kimberley coast, Western Australia. Records of the Western Australian Museum Supplement 81:125-144. DOI: 
806

807 Phillips BL., Baird SJE., Moritz C. 2004. When vicars meet: a narrow contact zone between

808

809

810

811

812

813

814

815

816

817

818

819

820

821

822

823

824

825

826

827 Ripley B., Venables B., Bates DM., Hornik K., Gebhardt A., Firth D., Ripley MB. 2013.

10.18195/issn.0313-122x.81.2013.125-144. morphologically cryptic phylogeographic lineages of the rainforest skink, Carlia rubrigularis. Evolution 58:1536-1548. DOI: 10.1111/j.0014-3820.2004.tb01734.x.

Potter S., Bragg JG., Peter BM., Bi K., Moritz C. 2016. Phylogenomics at the tips: inferring lineages and their demographic history in a tropical lizard, Carlia amax. Molecular Ecology 25:1367-1380. DOI: 10.1111/mec.13546.

Rabosky DL., Hutchinson MN., Donnellan SC., Talaba AL., Lovette IJ. 2014. Phylogenetic disassembly of species boundaries in a widespread group of Australian skinks (Scincidae: Ctenotus). Molecular Phylogenetics and Evolution 77:71-82. DOI: 10.1016/j.ympev.2014.03.026.

R Core Team. 2016. A language and environment for statistical computing.

Rambaut A., Suchard MA., Xie D., Drummond AJ. 2015. Tracer v1.6., Available from http://beast.bio.ed.ac.uk/Tracer.

Rannala B. 2015. The art and science of species delimitation. Current Zoology 61:846-853. DOI: $10.1093 /$ czoolo/61.5.846

Rannala B., Yang Z. 2013. Improved reversible jump algorithms for bayesian species delimitation. Genetics 194:245-253. DOI: 10.1534/genetics.112.149039.

Renner SS. 2016. A return to Linnaeus's focus on diagnosis, not description: the use of DNA characters in the formal naming of species. Systematic Biology 65:1085-1095. DOI: 10.1093/sysbio/syw032.

828 Package "MASS." Cran R. 
829 Rosauer DF., Blom MPK., Bourke G., Catalano S., Donnellan S., Gillespie G., Mulder E., Oliver

830 PM., Potter S., Pratt RC., Rabosky DL., Skipwith PL., Moritz C. 2016. Phylogeography,

831 hotspots and conservation priorities: an example from the Top End of Australia. Biological

832 Conservation 204:83-93. DOI: 10.1016/j.biocon.2016.05.002.

833 Rosenblum EB., Sarver B a J., Brown JW., Des Roches S., Hardwick KM., Hether TD., Eastman

834 JM., Pennell MW., Harmon LJ. 2012. Goldilocks meets Santa Rosalia: an ephemeral

835 speciation model explains patterns of diversification across time scales. Evolutionary

836 Biology 39:255-261. DOI: 10.1007/s11692-012-9171-X.

837 Singhal S., Moritz C. 2013. Reproductive isolation between phylogeographic lineages scales

838 with divergence. Proceedings of the Royal Society B: Biological Sciences 280:20132246.

839 DOI: $10.1098 / \mathrm{rspb} .2013 .2246$.

840 Storr GM. 1974. The genus Carlia (Lacertilia, Scincidae) in Western Australia and Northern

841 Territory. Records of the Western Australian Museum 3:151-165.

842 Sukumaran J., Knowles LL. 2017. Multispecies coalescent delimits structure, not species.

843 Proceedings of the National Academy of Sciences 2016:201607921. DOI:

$844 \quad$ 10.1073/PNAS.1607921114.

845 Wickham H. 2016. ggplot2: elegant graphics for data analysis. Springer.

846 Woerner AE., Cox MP., Hammer MF. 2007. Recombination-filtered genomic datasets by

847 information maximization. Bioinformatics 23:1851-1853. DOI:

$848 \quad 10.1093 /$ bioinformatics/btm253.

849 Xie W., Lewis PO., Fan Y., Kuo L., Chen M-H. 2010. Improving marginal likelihood estimation

850 for bayesian phylogenetic model selection. Systematic Biology 60:150. DOI:

$851 \quad 10.1093 /$ sysbio/syq085. 
852 Yang Z. 2015. The BPP program for species tree estimation and species delimitation. Current 853 Zoology 61:854. DOI: 10.1093/czoolo/61.5.854.

854 Yang Z., Rannala B. 2010. Bayesian species delimitation using multilocus sequence data.

$855 \quad$ Proceedings of the National Academy of Sciences of the United States of America 856 107:9264-9. DOI: 10.1073/pnas.0913022107.

857 Yang Z., Rannala B. 2014. Unguided species delimitation using DNA sequence data from 858 multiple loci. Molecular Biology and Evolution 31:3125-3135. DOI:

$859 \quad 10.1093 / \mathrm{molbev} / \mathrm{msu} 279$.

860

861 Figures

862
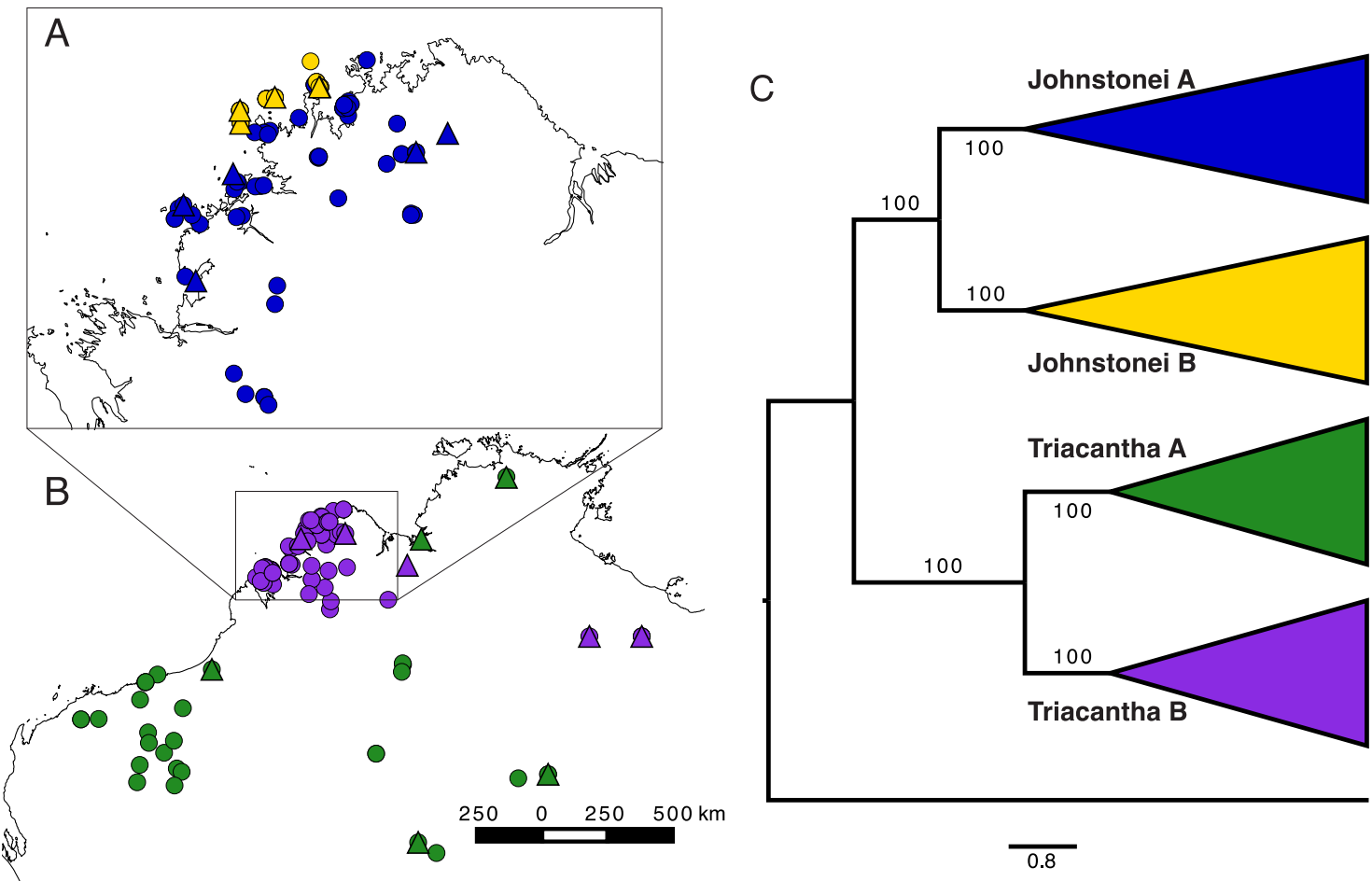

863 Figure 1 Distribution map with used genetic samples and measured specimens for C. johnstonei

864 (A) and for C. triacantha (B) lineages, and lineages relationships (C) as in Afonso Silva et al.

865 (2017). Triangles correspond to the genetic samples used in this study while circles correspond 
866 to specimens measured. Blue Johnstonei A, yellow Johnstonei B, green Triacantha A and purple

867 Triacantha B. Tree obtained with 20 representative samples in ASTRAL and respective lineage

868 bootstrap.

869

870

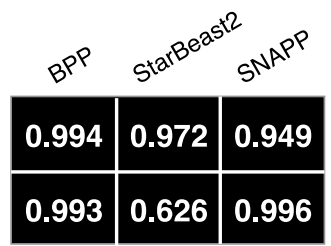

Johnstonei A

Johnstonei B

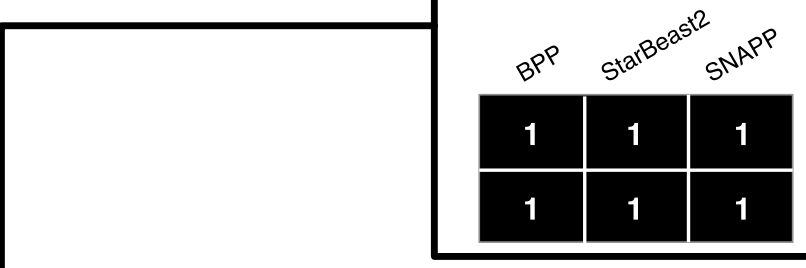

Triacantha A

Triacantha B

871 Figure 2 Species tree with topology from BFD StarBeast2 gene set1 presenting node

872 posterior probabilities for the two sets of data used for all three MSC methods. 

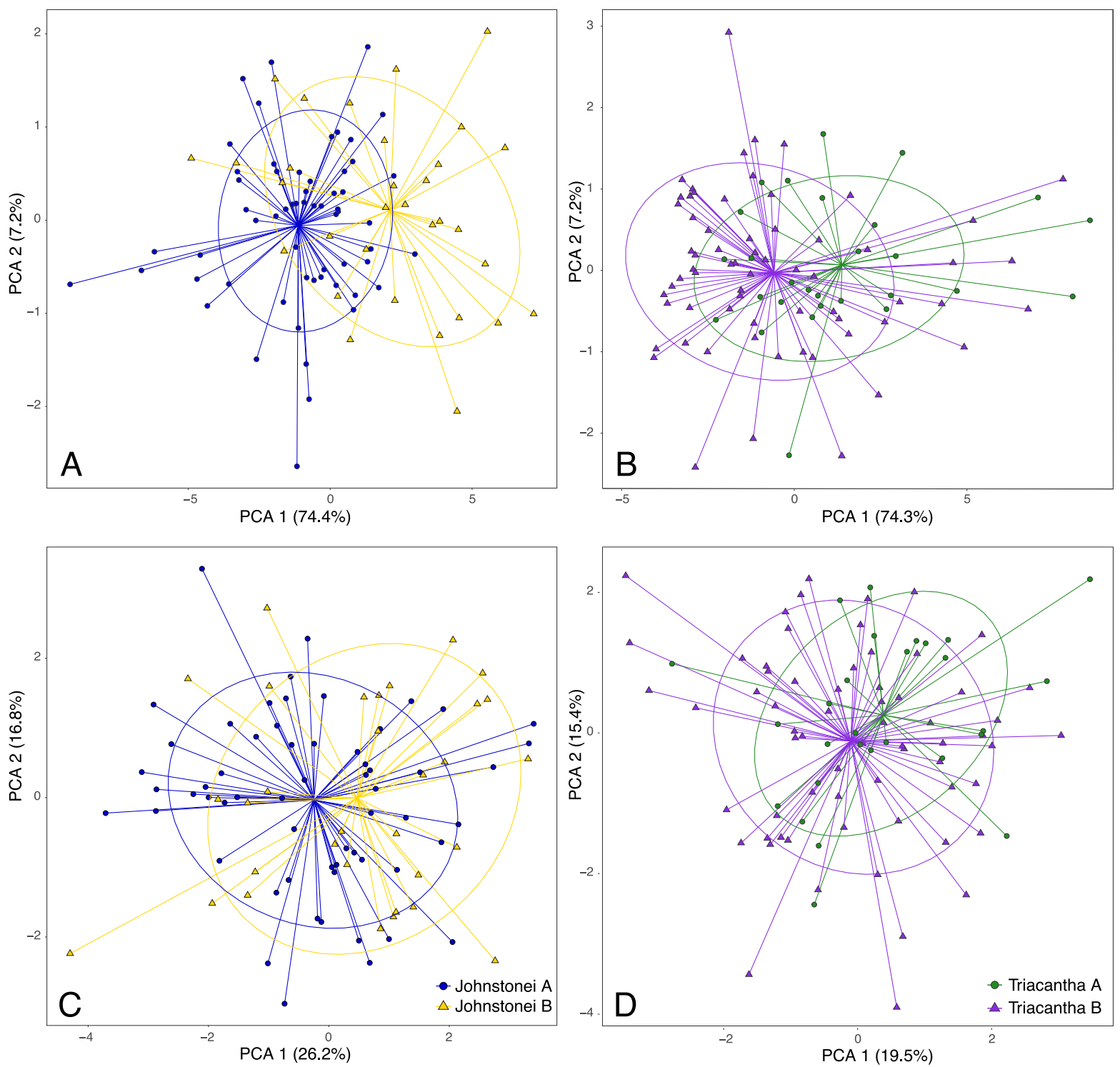

873

874 Figure 3 PCA with log transformed (A, B) and size corrected (C, D) morphological

875 measurements for $C$. johnstonei and for $C$. triacantha with colours by mtDNA lineage.

876

877 

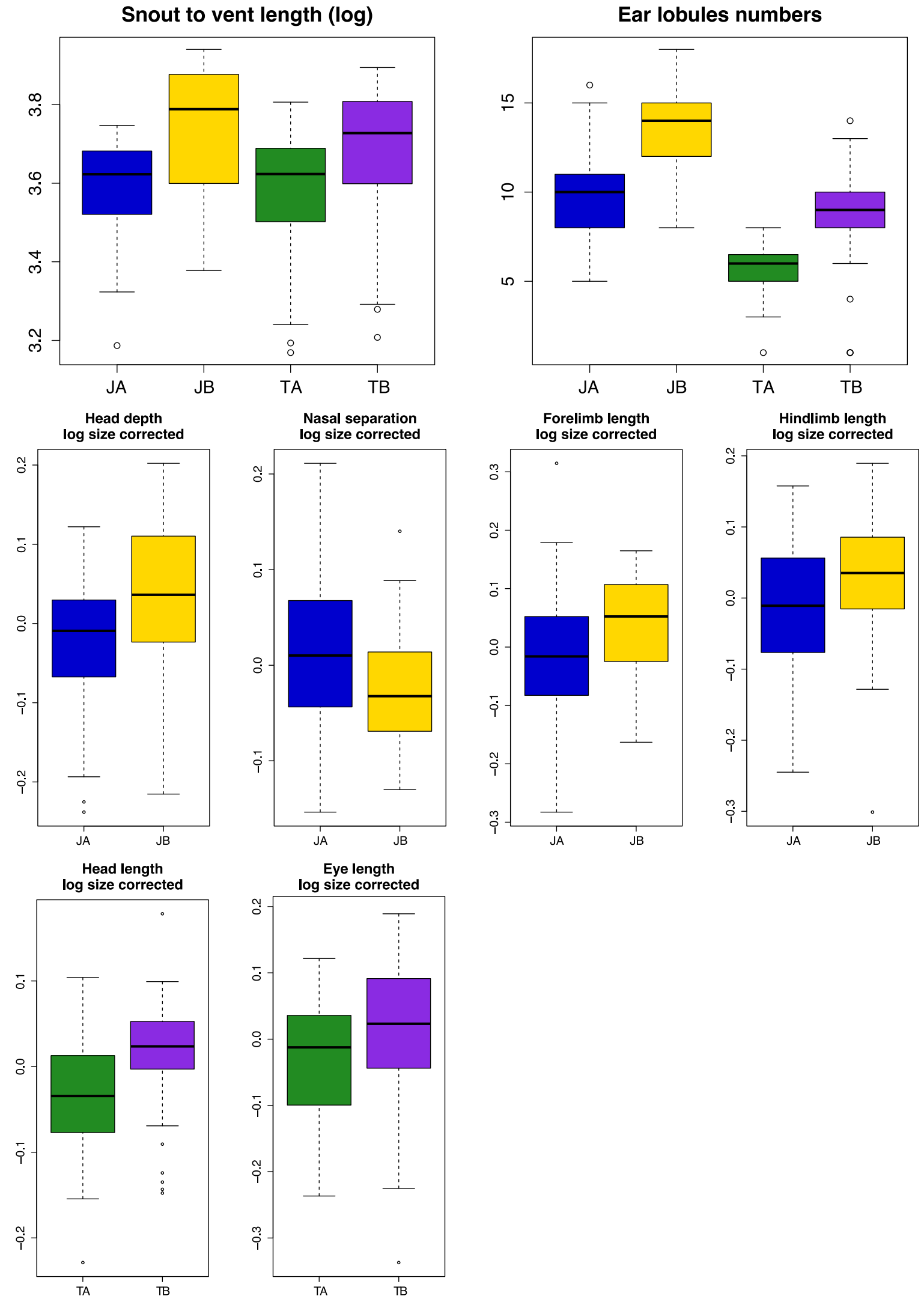
879 Figure 4 Boxplots of significantly different traits between mtDNA lineages for C. johnstonei and 880 for C. triacantha. JA - Johnstonei A, JB - Johnstonei B, TA - Triacantha A and TB - Triacantha 881 B.

882

883

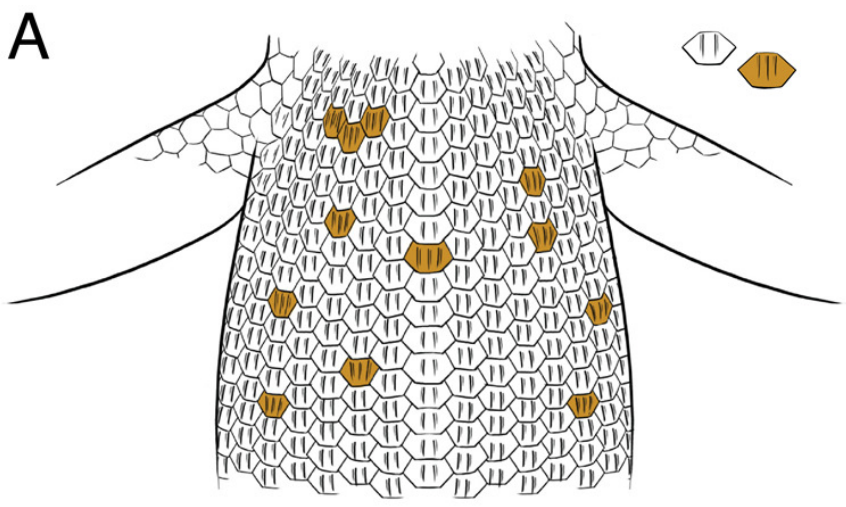

884
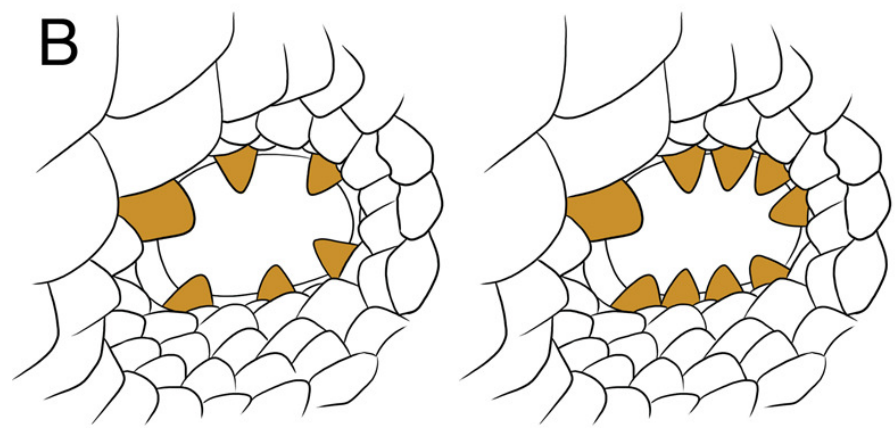

885

886 Figure 5 Relevant diagnostic traits. Irregular keeling in dorsal body scales for C. insularis sp.

887 nov. (A) and difference in ear lobules of C. triacantha (left) and C. isostriacantha sp. nov.

888 (right). Illustrations by Erin Walsh.

889

890

891 Tables

892 Table 1 Species delimitation support. For BPP support is in posterior probabilities while for BFD 
893 StarBeast2 and BFD* SNAPP is based in Bayes Factors calculated using the two species model 894 as the null model (two species support by comparing with the four species model).

895

\begin{tabular}{lcccccc}
\hline & $\begin{array}{c}\text { BPP } \\
\text { gene set1 }\end{array}$ & $\begin{array}{c}\text { BPP } \\
\text { gene set2 }\end{array}$ & $\begin{array}{c}\text { StarBeast2 } \\
\text { gene set1 }\end{array}$ & $\begin{array}{c}\text { StarBeast2 } \\
\text { gene set2 }\end{array}$ & $\begin{array}{c}\text { SNAPP } \\
\text { SNP set1 }\end{array}$ & $\begin{array}{c}\text { SNAPP } \\
\text { SNP set2 }\end{array}$ \\
\hline Two species & 0 & 0 & -318.10 & -274.04 & -4517.80 & -4443.35 \\
Three species & 0 & 0 & 223.35 & 203.79 & 3526.41 & 3370.49 \\
Four species & 1 & 1 & 318.10 & 274.04 & 4517.80 & 4443.35 \\
\hline
\end{tabular}

896

897 Table 2 ND4 mtDNA diagnostic SNPs for each lineage. The position of each SNP is aligned

898 with Scincella vandenburghi mitochondrial genome (Park et al. 2016). For each nucleotide

899 position is also presented the correspondent amino acid substitution. Grey background refers to

900 which species the SNP is diagnostic for.

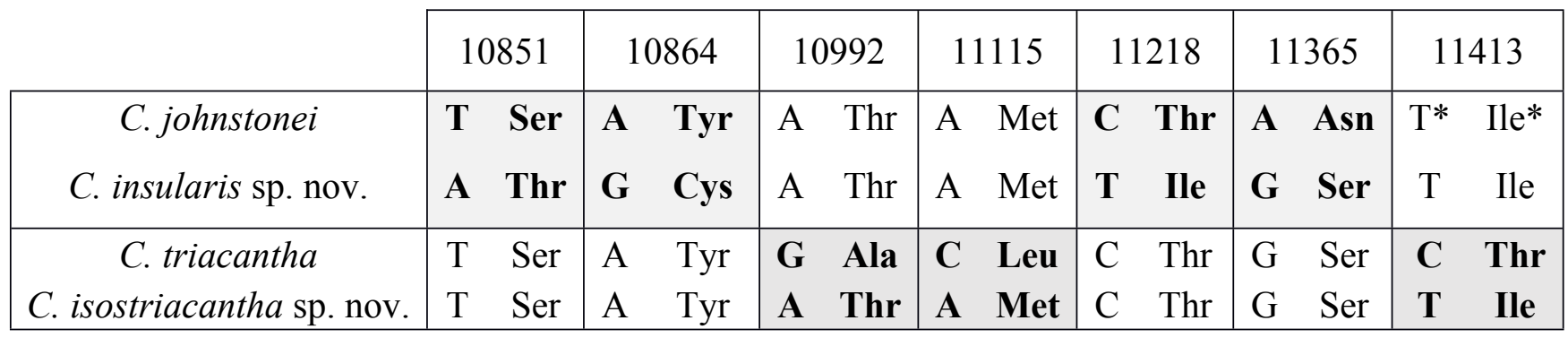

$901 *$ Substitution is not diagnostic for a few individuals

902

903

904 